\title{
Exploring the knowledge 'base' of practitioners in the delivery of sustainable regeneration projects
}

\author{
Julius Akotia ${ }^{1}$, Alex Opoku ${ }^{2}$, Charles Egbu ${ }^{2}$ and Chris Fortune ${ }^{3}$ \\ ${ }^{1}$ Kingston University, UK \\ ${ }^{2}$ London South Bank University, UK \\ ${ }^{3}$ Glyndwr University, UK
}

\begin{abstract}
In recent years, sustainable regeneration has been recognised as being of major economic and social concern in the world. In the UK for instance, government has initiated a number of policies and evaluation methods to deal with some of the environmental problems associated with regeneration projects. However, the post construction evaluation of these projects has often resulted in them being seen as not achieving their set objectives. Attempts aimed at evaluating the impact of sustainability by built environment practitioners have primarily been limited to their assessment of the projects' potential environmental impacts, with the associated socio-economic impacts being neglected. There has not been any well-defined built environment research that has been able to deal holistically with the broader issues of sustainability in terms of benefits/impacts of the regeneration projects to the communities concerned. The findings of an exploratory study that adopted a semi-structured interview approach for data collection, to explore the knowledge and understanding of fifteen practitioners who are often involved in the delivery of these projects are presented. The findings reveal a lack of knowledge and understanding of sustainability as well as structured mechanism/practices for evaluating the socio-economic sustainability factors in relation to regeneration projects.
\end{abstract}

Keywords: Knowledge and understanding, practitioners, sustainability benefit, sustainable regeneration.

Paper type: Research article

\section{Introduction}

The concept of sustainable development and regeneration has been an essential focal point of government policy for some time in the UK and it has contributed to the enhancement of many communities' physical structures (Haran et al, 2011). Many of the earlier initiatives that were meant to tackle socio-economic disparities have focused on improving the physical and environmental aspects of regeneration. In more recent times, there has been a number of research projects which sought to study and analyse how the UK built environment was/is responding to the challenges of integrating sustainability into regeneration projects (Dixon, 2006). The Sustainable Development Commission (SDC, 2003) suggested that the development of regeneration has proved to be a testing and on-going challenge for government agencies, construction industry practitioners and communities within the UK. The appreciation of such challenges has led to the development of various management strategies and systems to guide and

Copyright: Construction Economics and Building 2016. (C) 2016 Julius Akotia, Alex Opoku, Charles Egbu and Chris Fortune. This is an Open Access article distributed under the terms of the Creative Commons Attribution 4.0 Unported (CC BY 4.0) License (https://creativecommons.org/licenses/by/4.0/), allowing third parties to copy and redistribute the material in any medium or format and to remix, transform, and build upon the material for any purpose, even commercially, provided the original work is properly cited and states its license.

Citation: Akotia, J., Opoku, A., Egbu, C. and Fortune, C. 2016. Exploring the knowledge 'base' of practitioners in the delivery of sustainable regeneration projects, Construction Economics and Building, 16(2), 14-26. DOI: http://dx.doi.org/10.5130/AJCEB.v16i2.4892

Corresponding author: Alex Opoku; Email - opokua@1sbu.ac.uk

Publisher: University of Technology Sydney (UTS) ePress 
direct industry practitioners to achieve higher and improved sustainability standards. However, attempts aimed at delivering sustainability benefits have primarily been limited to the environmental performance of buildings. According to Brandon and Lombardi, (2011) previous works undertaken on sustainable regeneration have shown that they lack a conceptual clarity related to delivery of sustainability. Brandon and Lombardi, (2011) identified sustainable regeneration/development as an evolving field and suggested the need for further study, as they asserted that there had not been a well-defined study that has been able to deal with the core issues relating to delivering the socio-economic sustainability benefits/impacts of sustainability projects in a decisive manner. It is quite clear that the present project management systems, the industry practitioners and the governance structures as well as the nature of the evaluation mechanisms/practices all have an influence on the current construction industry practices related to the delivery of regeneration programmes. Consequently, the quest to deliver sustainable regeneration calls for an exploration of new ways to enable sustainable regeneration projects deliver the core sustainability objectives in a holistic manner that maximises the sustainability benefits for the communities concerned.

The main aim of the study is to explore the knowledge and understanding of practitioners involved in the delivery of sustainable regeneration projects in the UK. The knowledge and understanding of practitioners involved in the delivery of sustainable regeneration, meant to deliver sustainability benefits in the UK is explored in this paper. The paper starts by providing literature background on sustainable development and regeneration. A discussion (preceded by a brief literature review on the issue) is then presented on the findings from an exploratory study that adopted semi-structured interviews with fifteen practitioners of leading construction industry organizations involved in sustainable regeneration projects in the UK, and draws a conclusion. The work draws from on-going research which is concerned with the development of a framework for socio-economic benefit evaluation of regeneration projects in the built environment.

\section{Sustainable regeneration: a driving force for sustainable development}

The transformation of the urban environments has often been viewed largely in physical terms, for instance, the construction of new a hospital, school, housing etc. in a community (Boyko et al., 2006). The post war era has seen a significant number of such transformations in the form of regeneration schemes, designed to improve the social and economic well-being of areas that have experienced a dramatic decline in their socio-economic fortune (CLG, 2010). A seminal work by Roberts (2000, p.17) defines regeneration as:

"a comprehensive and integrated vision and action which leads to the resolution of urban problems and which seeks to bring about a lasting improvement in the economic, physical, social and environmental condition of an area that has been subject to change."

Roberts' work established the baseline for sustainable regeneration initiatives and the need to view regeneration activities as an integrated and comprehensive approach which requires a greater balance between the creation of the physical environment and socio-economic development of the communities. The Department for Community and Local Government report outlined the need to strive for a greater balance between the creation of the physical environment and the creation of sustainable communities where people want to live and feel secure (CLG, 2009). Traditionally, the UK regeneration strategy has focused on housing conditions of the poorer communities (Lawless, Oveman and Tyler, 2011). It sets out an agenda for the provision of quality housing facilities to meet the needs of society in a comprehensive and integrated manner to contribute towards the creation and maintenance of sustainable communities. Fundamentally, regeneration is about closing gaps (Community and Local Government (CLG), 2010) and tackling the spatial disparities that exist within the communities 
(HM Treasury, 2007). It also means meeting the needs of the people in a way that delivers social progress, economic growth, environmental protection, and better quality of life (OGC, 2007; SDC, 2003).

The sustainable regeneration concept according to CLG, (2008) has covered a wide range of different initiatives which have operated at various spatial levels (CLG, 2008). Central to the regeneration concept is the potential to create a society that can become socially and economically viable and self-sustaining (Adair et al., 2003). It is regarded, largely, as the most essential form of intervention and action to solve the developmental needs of the people, by addressing existing needs for present and the future generations (Granger, 2010). CLG, (2008) pointed out that the pursuance of regeneration intervention can be justified for the reason that it helps to deal with equity issues existing within the society, particularly in situations where there are undesirable disparities in peoples' living conditions as a result of inequitable distribution of social and economic sustainability factors. It is also suggested that laying more emphasis on socio-economic factors of sustainability and integrating them into the regeneration delivery process will assist in tackling such developmental gaps the concepts are designed to address in a decisive manner (SDC, 2003). Therefore, the need to meet these demands calls for regeneration initiatives that recognise the importance of such socio-economic sustainability factors as the key indicators of sustainable regeneration.

The notion that regeneration is about creating places where people want to live and work should mean that the delivery of adequate sustainability factors would have to be achieved to help satisfy the notion. It is suggested that sustainable regeneration would be successful if adequate attention is given to the current practices in responding effectively to the current challenges posed by the sustainable development agenda. Yet the traditional project management and delivery approaches adopted to deliver such regeneration objectives has accounted for their failure (Sorrell and Holti, 2007). It has also been suggested that many of such regeneration initiatives have been planned without the fundamental components of sustainability as a parallel strand, resulting in the inability of regeneration projects to deliver on such shared objectives underlying sustainable development.

The UK government Audit Commission (2007) report has revealed that many regeneration activities are yet to have a consistent and positive impact on most deprived localities. The report suggested that the level of long-term unemployment in the communities where regeneration initiatives have taken place has remained static, and targeted work to develop skills and access to employment for these communities still remains under developed. The bottom line is that regeneration shares many goals with sustainable development, therefore any effort aimed at improving the efficiency of regeneration projects should pay greater attention to the sustainability factors. However, to deliver such sustainable regeneration goals as advocated by the UK government reports (CLG, 2009; 2010) and Roberts (2000) will require a strong and strategic approach to sustainable regeneration development to meet local needs. Since socio-economic disparities are seen to be directly rooted in our community set-up, focusing on sustainable regeneration has enormous potential to drive the local communities towards becoming sustainable communities (Smith, 2006). An empirical study by Coaffee (2004) suggested that the previous attempts to deliver regeneration programmes were seen to be lacking the vision of improving the local communities in a way that meets the sustainable development requirements of the area. A subsequent study by Granger, (2010) supported this view by suggesting that much of what has been perceived to be sustainable regeneration in recent years in urban communities has been redevelopment rather than regeneration. Granger went on to argue that, the objectives of such regeneration projects has been on the improvement of the physical 'appearance' rather than addressing the socio-economic needs of the communities concerned, hence their inability to address the fundamental objectives underlying sustainable regeneration initiatives. It is believed that if future regeneration is to make greater sustainable impact on the communities concerned 
then the current regeneration projects' priorities will have to be altered to reflect the priorities needed to achieve the sustainable development objectives of the affected communities (Raco and Henderson, 2009).

\section{Sustainable regeneration project drivers}

The construction industry has been recognised as a major driver in the delivery of the UK sustainable development and regeneration agenda (DBIS, 2013). The UK government's strategy to deliver sustainable development sets the agenda and challenged the construction industry to drive its operations in a manner that delivers sustainable products to achieve the sustainable development and regeneration objectives. The industry is being called upon to shift from its traditional way of delivering sustainability projects to a more modernised one which will ultimately lead to improving the sustainability performance of their projects (DBIS, 2013). Delivering the objective of sustainable regeneration practices across the industry is a challenging process which requires a paradigm change if the industry is to achieve sustainable regeneration and remain competitive. Traditionally, the construction industry has been driven by cost, time and quality objectives (Cruickshank and Fenner, 2007), and the consideration of sustainability adds to these objectives. Striving to achieve sustainable regeneration calls for the adoption of sustainability practices in a manner that makes projects achieve their sustainability benefits for society and the organisations providing the projects (Shen et al., 2010). Promoting the concept of sustainable regeneration also has enormous potential to drive the society towards the attainment of sustainability objectives. It has been argued that many sustainable regeneration features share many goals with sustainable development features. Hence, the attainment of sustainable regeneration can be the determinant of sustainable development.

The UK government's White Paper published in 2000 on regeneration and renewal which sets out the government's plans to drive regeneration of communities, recommended the need to improve the sustainability benefits of society with sustainable regeneration initiatives (CLG, 2008). Generally the performance of regeneration projects is demonstrated and driven by many of the opportunities created by these regeneration projects. In a series of stakeholder consultation events reported in CLG (2008), the majority of participants suggested that socio-economic development should be seen as a key driver for sustainable regeneration outcomes. The participants emphasised the need for sustainable regeneration to pay a greater attention to deliver tangible sustainability benefits in a holistic manner. It has been acknowledged that a significant number of regeneration initiatives, which have been formulated to deliver such range of regeneration projects, have been driven by a number of factors (CLG, 2010). Notable influencing factors reported to be driving most practitioners and their organisations in promoting sustainability in the UK included: incentive mechanisms, government policy frameworks and legislations on green buildings, etc., (Turcsanyi and Sisaye, 2013).

Empirical work by Pitt et al., (2009), which collected data from 200 Royal Institute of Chartered Surveyors (RICS) members in the UK, has also found financial incentives, building regulations, lack of client awareness and demand as the most influential factors that were driving many construction industry organisations to promote sustainability on their projects. Other drivers identified by Turcsanyi and Sisaye (2013) in line with Pitt et al., (2009) findings for adopting sustainability principles included; image or reputation improvement, meeting ethical and moral obligations as well as the improvement of overall economic fortune of their organisations. It is asserted that the improvement of sustainability content in regeneration projects goes beyond just using environmental and sustainability materials to deliver the projects. It is also about getting the right sustainability policy drivers and strategies in place to deliver all the sustainability aspects particularly, in sustainable regeneration projects. In this regard, promoting economic sustainability factors such as sustainable jobs and inward investments to boost economic growth has become very important for regeneration projects. Likewise, the promotion of social 
sustainability factors such as the promotion of skills development, health and safety and security, and housing are crucial to enable people to feel safe and happy to live in a particular area (SDC, 2003). Integrating the core elements of sustainability in regeneration processes and practices offers a considerable opportunity for construction organisations to run a responsible business. According to Weber (2008), promoting good sustainability practices could potentially lead to cost savings and reductions in financial risk for the organisations in the long term. Similarly, it is suggested that the achievement of a higher standard in sustainability performance of an organisation could influence the attraction and retention of employees. In this respect, it can therefore be argued that, by promoting sustainability factors the construction industry is more likely to deliver substantial sustainable regeneration benefits through the projects.

\section{Research approach}

In order to explore the main sustainability issues to meet the objectives of the study, a qualitative research approach was adopted using semi-structured interviews to collect data. This approach reflected an interpretivist philosophical position that made use of inductive research strategy and qualitative methodology. A major advantage associated with a qualitative research approach involves its capacity to produce more detailed explanations of human phenomena through the use of personal interviews (Petty, Thomson and Stew, 2012). According to Qu and Dumay (2011), the application of interviews provides a powerful means to discover new knowledge and capture the account of experts in the field in a more open, consistent and systematic manner that the standardised methods, such as questionnaire surveys are unable to do. Saunders, Lewis and Thornhill, (2009) argued that a personal interview approach involving one-to-one interactions can also provide an opportunity for the researcher to take a record of the interviewees' nonverbal communications. Initially, twelve (12) leading construction organisations in the UK were selected, based on their involvement in the delivery of sustainable regeneration projects, through a purposive sampling technique. Formal letters were then sent out to these organisations as an invitation to participate in the study. Follow up telephone calls were also made to these organisations to explain further the purpose and the context of the study. In all, three construction organisations agreed to participate in the study. Face-to-face in-depth semistructured interviews were then conducted with the fifteen (15) practitioners, with interviews lasting between 45-60 minutes, to explore the knowledge and understanding of the following issues in relation to the delivery of sustainable regeneration projects:

\section{Sustainability Factors}

2. Evaluation and evaluation mechanisms/practices

3. Promotion of socio-economic impact/benefits.

Each of the three agreed construction organisation was made up of five (5) key practitioners: architect, project manager, commercial manager, sustainability manager, and regeneration manager. A profile of sustainable regeneration practitioners interviewed is shown in Table 1 . The interviews were conducted in an interactive and open manner with a minimum interview structure in an attempt to obtain more detailed information and also to gain a deeper appreciation of the issues with practitioners (Denzin and Lincoln, 2008). The interviews were formatted around a range of open-ended questions to explore the issues under investigation. All the interviews were recorded and later transcribed verbatim, to allow for subsequent content analysis of the interview data. The responses were further analysed to identify the emerging issues in the current practices related to practitioners' knowledge and understanding in relation to the delivery of sustainable regeneration projects. 
Table 1: Profile of sustainable regeneration practitioners interviewed

\begin{tabular}{|c|c|c|c|c|c|c|}
\hline $\begin{array}{l}\text { Construction } \\
\text { Organisation }\end{array}$ & Organisation 1 & $\begin{array}{l}\text { Work } \\
\text { experience }\end{array}$ & Organisation 2 & $\begin{array}{l}\text { Work } \\
\text { experience }\end{array}$ & Organisation 3 & $\begin{array}{l}\text { Work } \\
\text { experience }\end{array}$ \\
\hline \multirow{5}{*}{$\begin{array}{l}\text { Practitioners } \\
\text { Role }\end{array}$} & Architect (AR1) & 12 years & Architect (AR2) & 15 years & Architect (AR3) & 20 years \\
\hline & $\begin{array}{l}\text { Project manager } \\
\text { (PM1) }\end{array}$ & 15 years & $\begin{array}{l}\text { Project manager } \\
\text { (PM2) }\end{array}$ & 13 year & $\begin{array}{l}\text { Project manager } \\
\text { (PM3) }\end{array}$ & 18 years \\
\hline & $\begin{array}{l}\text { Commercial } \\
\text { manager (CM1) }\end{array}$ & 15 years & $\begin{array}{l}\text { Commercial } \\
\text { manager (CM2) }\end{array}$ & 18 year & $\begin{array}{l}\text { Commercial } \\
\text { manager (CM3) }\end{array}$ & 20 years \\
\hline & $\begin{array}{l}\text { Sustainability } \\
\text { manager (SM1) }\end{array}$ & 10 years & $\begin{array}{l}\text { Sustainability } \\
\text { manager (SM2) }\end{array}$ & 12 years & $\begin{array}{l}\text { Sustainability } \\
\text { manager (SM3) }\end{array}$ & 16 years \\
\hline & $\begin{array}{l}\text { Regeneration } \\
\text { manager (RM1) }\end{array}$ & 12 years & $\begin{array}{l}\text { Regeneration } \\
\text { manager (RM2) }\end{array}$ & 14 years & $\begin{array}{l}\text { Regeneration } \\
\text { manager (RM3) }\end{array}$ & 15 year \\
\hline
\end{tabular}

Table 2 presents the results of the responses provided by practitioners during the semi-structured interviews. During the analysis, it became apparent that there were primarily two main categories of responses from practitioner as shown in Table 2.

Table 2: Interview results of practitioners

\begin{tabular}{|c|c|c|c|c|c|c|}
\hline \multirow[t]{3}{*}{ Practitioners / Issues } & \multicolumn{6}{|c|}{ Practitioners Total $\mathrm{N}=15$} \\
\hline & \multicolumn{2}{|c|}{ Sustainability factors } & \multicolumn{2}{|c|}{$\begin{array}{l}\text { Evaluation and } \\
\text { evaluation mechanisms }\end{array}$} & \multicolumn{2}{|c|}{$\begin{array}{l}\text { Promoting socio-economic } \\
\text { sustainability benefits }\end{array}$} \\
\hline & $\mathrm{a}^{*}$ & $b^{*}$ & $a^{*}$ & $b^{*}$ & $a^{*}$ & $b^{*}$ \\
\hline Architect & 1 & 2 & 1 & 2 & 1 & 2 \\
\hline Project manager & 1 & 2 & - & 3 & 1 & 2 \\
\hline Commercial manager & - & 3 & - & 3 & - & 3 \\
\hline Sustainability manager & 1 & 2 & 1 & 2 & 1 & 2 \\
\hline Regeneration manager & 1 & 2 & 1 & 2 & 1 & 2 \\
\hline \multirow[t]{2}{*}{ Total $\mathbf{N}=15$} & 4 & 11 & 3 & 12 & 4 & 11 \\
\hline & $(26.7 \%)$ & $(73.3 \%)$ & $(20.0 \%)$ & $(80.0 \%)$ & $(26.7 \%)$ & $(73.3 \%)$ \\
\hline
\end{tabular}

$\mathbf{a}^{*}$ : Number and percentages (\%) of practitioners (interviewees) whose responses either indicated adequate/good understanding issues. $\mathbf{b}^{*}$ : Number and percentages (\%) of practitioners (interviewees) whose responses either indicated some/limited understanding of the issue

\section{Discussion of results}

\section{Sustainability factors}

It has been said that sustainability features in regeneration projects are multifaceted and often subjected to different processes and interpretations during different stages of the project. Feige, Wallbaum and Krank (2011) pointed out that the sustainability concept in itself causes various forms of challenges to different groups of practitioners. Several studies have claimed that many 
practitioners have only demonstrated a relatively limited understanding, leading to the adoption of relatively weak processes towards the promotion and implementation of key sustainability principles in practice (Lombardi et al., 2011). The first interview question put to the practitioners explored their knowledge and understanding of sustainability, and the importance practitioners and their organisations have attached to sustainability factors during the delivery of their regeneration projects. A significant theme that emerged from their responses was the lack of conceptual clarity and understanding of sustainability factors by practitioners. While all the practitioners who participated in the study have had at least ten years of experience in the delivery of sustainable regeneration projects over the years, the results obtained from interview indicate that only $4(26.7 \%)$ of the 15 practitioners interviewed demonstrated some good knowledge and understanding of sustainability issues in relation to sustainable regeneration projects. However, the majority, $11(73.3 \%)$ of the 15 practitioners who participated in the interview provided relatively simplistic definitions and understanding of sustainability in relation to their business operations. A typical comment given by one of the practitioner's, SM1 for instance was;

Sustainability is something ingrained and inherent in our business processes something that the business has to pay attention to in order to stay competitive... It is about protecting our business from the risks of today and ensuring that we respond to the challenges and opportunities that tomorrow brings

The above was further buttressed by one of the commercial mangers, CM2, who also commented by saying:

Sustainability is one of the key driving forces bebind our operations. ... First and foremost it fits with the vision and values of our business. ... sustainability makes us competitive in the environment we operate... It helps us to reduce our carbon footprint, enhances our long-term value.

Similarly, one of the architects, AR1, who had been involved in the design and delivery of regeneration projects for the past twelve years, also provided his views in line with their design solution by saying:

\section{Is about achieving the right balance through our innovative design solution and area transformation, while maintaining a clear focus on the overall objectives of creating a robust infrastructure and services}

Surprisingly, it was further noticed that practitioners who have sustainability assigned to their roles/responsibilities (regeneration managers, sustainability managers) were among the practitioners who showed little knowledge and understanding of sustainability issues. Largely, their responses highlighted the limitation in the practitioners' knowledge and understanding of sustainability. The ambiguity of what constitutes sustainability was also identified as a major problem in the works done by Evans and Jones, (2008) and Brandon and Lombardi, (2011). Much of the sustainable construction literature has shown that sustainability issues have not been well understood and translated into practice by practitioners (Carter and Fortune, 2007). Many of the misapplications of sustainability contents in regeneration projects arise from practitioners' appreciation of sustainability issues. Delivering sustainable regeneration projects is about the understanding and responsibility of all the key practitioners to contribute to the delivery of the projects. Practitioners such as project managers and others with sustainability responsibilities are crucial in the sense that their knowledge and understanding of sustainability will enable them to deliver sustainability requirements of their projects. A widely held view is that sustainability aspects of the regeneration projects will be more enhanced if the sustainability elements of the projects are well understood. It is believed that project teams, if well-formed, would be able to understand what is required to be achieved for the project in the context of sustainability (Mathur, Price and Austin, 2008). Sustainable regeneration deliverables if not well understood and prioritised appropriately can lead to trade-offs between projects' objectives and organisational interests. 


\section{Evaluation and evaluation mechanisms/practices}

According to Kazmierczak, Curwell and Turner, (2009) the evaluation process provides an effective management mechanism on which decision-makers can base their judgement in a variety of ways. The primary objective of carrying out evaluation is to learn lessons, both positive and negative, which can be used to inform decision making on future activities and delivery of projects (HM Treasury, 2011; Jack and Breeze, 2008). Showing good understanding of evaluation mechanism could potentially help to overcome the challenges inherent in the current delivery of sustainability. However, the extent to which regeneration projects can be seen to be sustainable will largely depend on practitioners' knowledge and understanding of the evaluation mechanisms and systems on which the evaluation practices are based. In a study conducted by Williams, et al. (2013), nearly $85 \%$ of practitioners who participated in the study were of the view that conducting evaluation could contribute to learning and also assist in improving the project sustainability performance of sustainability projects. Hence, in exploring the evaluation mechanisms and the current practices related to the evaluation of sustainability on regeneration projects, it was revealed that only $3(20.0 \%)$, notably one architect, one regeneration manager and sustainability manager, demonstrated a good appreciation of evaluation mechanism/practices related to evaluation of sustainability factors on their projects. The analysis of the results further showed that majority of the practitioners $12(80.0 \%)$ did not demonstrate good understanding and knowledge of evaluation mechanism/practices for the evaluation of sustainability factors on regeneration projects.

One major issue which became apparent during the interview was the misconception between evaluation mechanisms/practices and assessment methods. Some of the practitioners were confusing the evaluation mechanism/practices with the assessment methods. Many of the practitioners have cited BREEAM as being the main evaluation mechanism used for their projects. As noted by one of the practitioners AR2:

BREEAM is the main assessment method used for our projects as it focuses on low or zero carbon technologies and designs...It is a vital part of our culture and scheme to promote the adoption of cohesive sustainable solutions across all our specialism as a best practice to meet our sustainability objectives.

Commenting on the issues, another practitioner PM3; expressed his views in line with the above comment by saying;

BREEAM is easy to use as it provides a guideline and specifies the environmental impact of the final products. BREEAM ultimate benefits are recognisability in a sense that it tends to capture the main environmental aspects of projects... Compliance with the existing environmental legislation and principles and best practices.

From the above results it can clearly be deduced that sustainable regeneration practitioners still consider environmental factors to be the most dominant feature of sustainability factor of sustainable regeneration projects. Most of the practitioners emphasised the environmental credentials of BREEAM and also regarded its application as representing the industry's best practice relating to the delivery of sustainability. It is worth noting that BREEAM parameters are prescriptive in nature and largely based on quantitative assessment which tends to ignore the processes and issues relating to socio-economic factors of sustainability of the projects. This finding is also consistent with the earlier work by Essa and Fortune (2008). When asked further about just when the evaluation frameworks were being applied during the project delivery stage, there were mixed responses. For example one practitioner PM1 who has been working on regeneration projects over the past fifteen years, noted that:

This varies from project to project. If our property business is involved then we are involved at concept stage through design and construction. Most of the time we would be contracted at RIBA stage D and E. 
Furthermore, one practitioner SM2 commented that:

the project life cycle stage ultimately depends on the nature and duration of the project...We adopt a flexible and innovative approach based on the requirements of the project we are involved in by demonstrating compliance with the specific targets and key performance indicators agreed by all parties on sustainability relating to the construction and operation of the facility.

Similarly, another practitioner RM1 who alluded to the use of some form of evaluation mechanism/practices by saying;

We do not have a structured evaluation framework per se, what we do have is some models for planning and benchmarking...Y Yes we tend to apply our models throughout our project duration to identify and address actions as soon as possible where the greatest sustainability impact may be available... This provides our sustainability team with a brilliant opportunity to look at a broad range of performance issues against the set of our sustainability targets and benchmarks.

Evidence from this finding provides the indication of lack of appreciation of evaluation mechanism/practices as well as the lack of a structured evaluation mechanism and practices and the use of structured evaluation process by practitioners for evaluating sustainability benefits/impacts of their sustainability projects. The finding further reinforces the works done by authors such as Jack and Breeze (2008) and McQuaid, Greig and Lindsay, (2006). Drawing from this finding, it can be observed that the challenges underlying the current delivery of sustainability projects lie on the inadequacy of practitioners' knowledge and appreciation of evaluation mechanism and practices. It is believed that the extent to which a successful evaluation of regeneration impact can be achieved will largely depend on the extent to which practitioners' are able to demonstrate a good understanding of evaluation mechanisms/practices. Doing so would enable them to undertake evaluation of sustainability factors; learning and ascertaining the sustainability benefits of their regeneration projects.

\section{Promoting socio-economic sustainability impact/benefit}

There are seemingly numerous definitions and criteria of socio-economic sustainability factors in literature and in practice. Different practitioners sought to define and adopt the socio-economic sustainability factors based on their understanding, perceptions and interest. While socioeconomic sustainability factors are crucial in developing and building a vibrant society, it is imperative that their factors and benefits are well understood and clearly set out by practitioners. From the finding in table 2, it was observed that, of the 15 practitioners who participated in the semi-structured interviews, only $4(26.7 \%)$ have demonstrated a good understanding and knowledge of socio-economic sustainability benefits and its promotion on sustainable regeneration projects. Akin to the finding obtained above, majority of practitioners, $11(73.3 \%)$ clearly showed the lack of appreciation of the main benefit/impact of socio-economic sustainability factors and how it should be promoted and incorporated into their regeneration projects. Although all the practitioners interviewed were involved in the delivery of sustainable regeneration projects, their responses indicated a limited knowledge and understanding of socioeconomic factors and impact of sustainable regeneration projects. An observation which was further made from the responses was the apparent misconception which was noted between sustainable regeneration projects and community redevelopment/renewal projects. A notable response which highlighted this misconception (when asked about the main socio-economic sustainability factors being promoted that were generating benefits for the community) was made by one of the practitioners AR2. He intimated that the promotion of socio-economic sustainability factors and benefits of their projects on the community where they were working was about promoting and ensuring: 
Creation of public amenity, the improvement of public access on site and improved existing wildlife habitats that will encourage greater biodiversity on site...Redevelopment of site for use of both commercial/ residential and public open spaces.

Another practitioner PM3, with eighteen years involvement in delivery of regeneration projects also expressed his candid views by indicating that:

It is the social and economic impacts that we find most problematic. Our main goal across all our disciplines is to take a responsible attitude toward renewal of our communities. ...We are keen on providing modern community facilities, improving the physical environment of our communities as well as safeguarding the environment as a whole for the benefit of our communities.

The above finding further corroborates the earlier works of Mang and Reed (2012) and Littig and Griebler (2005) in which it was observed that, among the sustainability factors, the socioeconomic factors were the most ignored and also difficult to promote in terms of their composition, adoption and evaluation on sustainability projects. It has been acknowledged that, a significant number of regeneration initiatives which have been formulated to deliver regeneration projects over the years, have been driven based on practitioners' priorities for the projects. According to Lombardi et al. (2011) and Van Bueren and De Jong (2007), the lack of limited understanding of the associated with sustainability has played a significant role in not adequately promoting the core sustainability factors in practice, as required. Many of the practitioners expressed their views in line with the potential environmental benefits of a project and also gave emphasis to sustainability factors that fitted within their own understanding and agenda (Evans and Jones, 2008). The limited appreciation given to socio-economic sustainability factors in practice was also identified in a study carried out by Carpenter (2011). Similarly, the over reliance on environmental factors has also played a significant part in limiting the integration of socioeconomic sustainability factors into the mainstream practices of practitioners. A study by Lombardi et al. (2011) suggested that the tenets of sustainability are quite often limited to environmental solution rather than adopting a more comprehensive approach to regenerating the communities. From the finding it is logical to suggest, that the current level of promotion and implementation of socio-economic sustainability factors and benefits on sustainable regeneration projects can be said to be a reflection of practitioners' knowledge and understanding of the main sustainability factors of sustainable regeneration projects. Indeed, it is believed, that if future regeneration projects are to deliver their intended sustainability benefits, then it is crucial that adequate emphasis is given to addressing the knowledge and skills sets of practitioners who deliver these projects (CLG, 2008).

\section{Theory and practice - the current gap and barriers}

Much of the sustainable regeneration literature has shown that the concept of sustainability has not been well understood by many stakeholders within the built environment. The concept of the 'triple bottom line' of sustainability places equal importance on the economic, social and environmental dimensions (Essa and Fortune, 2008) which are fundamental ingredients in any regeneration project. The gap and barriers identified within the exploratory study with the practitioners are illustrated in Figure 1. The current gap and barriers existing between theoretical concepts and the 'reality' in practice was revealed from the findings, as the majority of practitioners who participated in the study demonstrated a lack of knowledge and understanding of sustainability and consistently placed emphasis on the environmental sustainability factors at the neglect of the socio-economic sustainability factors and benefits of the projects. This was evident in the trend of responses of all the three issues explored, as illustrated in Figure 1, in which practitioners' practical knowledge and understanding of sustainability has acted as a major barrier to the promotion and pursuance of socio-economic sustainability factors in practice. Following the exploration of the issues with the practitioners, it can be seen that the challenges 
associated with the current delivery of regeneration projects are products of the key players' knowledge, perception and understanding of sustainability. Consequently, this is reflected in the way sustainability has been articulated and applied in practice (see Fig.1). It can also be suggested that the high emphasis placed on the environmental features could partly be attributed to the government policy on green building and the existing evaluation tools such as the BREEAM which are focused on measuring the environmental impacts of projects. However, it is argued that environmental sustainability by itself cannot function properly in any successful regeneration project, if it is not accompanied and complimented by social and economic benefits.

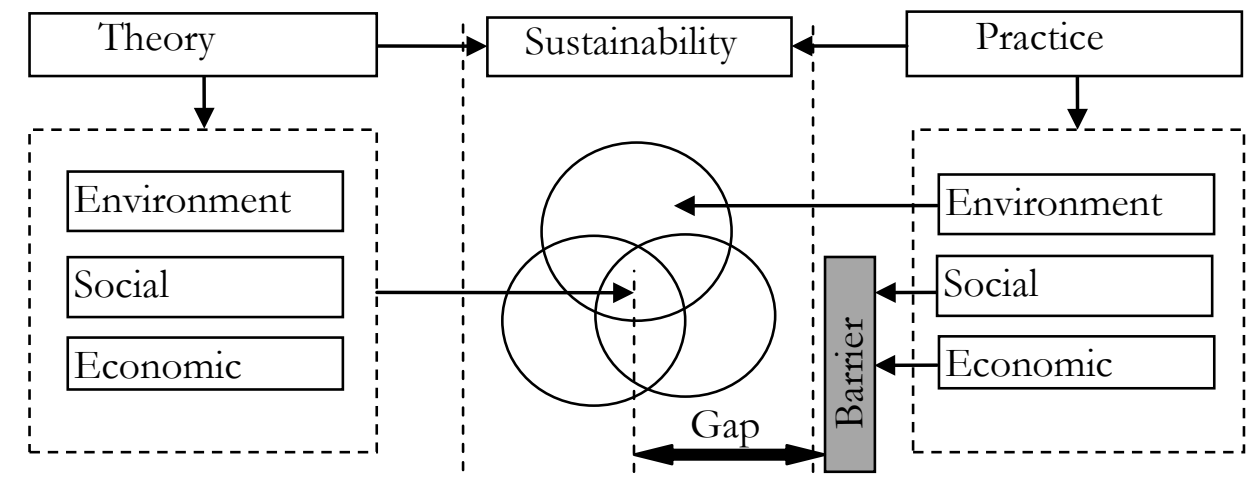

Figure 1: Conceptualised summary of findings

\section{Conclusion}

The study explored the knowledge and understanding of practitioners involved in the delivery of sustainable regeneration using a semi-structured interview approach to collect data from fifteen (15) sustainable regeneration practitioners. It was revealed from the findings that, while all the practitioners seemed to have accepted the sustainability concept in principle, their responses indicated a lack of appreciation of the wider meaning and understanding of the composition of sustainability in relation to sustainable regeneration projects. The study also identified a disparity between the theoretical concept and the reality in practice of sustainability factors on a personal and organisational level. The findings from the study further established that the consideration of sustainability was still viewed as being concerned with environmental issues by practitioners to the neglect of the socio-economic factors in sustainable regeneration projects. Another major limitation identified in the interviews, was the lack of structured evaluation processes or mechanisms for evaluating the socio-economic sustainability impact/benefits of sustainable regeneration projects. The results of this exploratory study support the need to collect more data from other built environment regeneration projects to enhance the reliability of the findings.

\section{References}

Adair, A., Berry, J., McGreal, S., Hutchison, N., Watkins, C. and Gibb, K., 2003. Urban regeneration and property investment performance. Journal of Property Research, 20(4), pp.371-86. doi: http://dx.doi.org/10.1080/0959991042000181994

Audit Commission UK, 2007. Service Inspection Report, Regeneration, West Lindsey District Council. UK: Audit Commission.

Brandon, P.S. and Lombardi, P., 2011. Evaluating sustainable development: in the Built Environment. 2nd ed. London: Wiley and Sons Publication.

Boyko, C.T., Cooper, R., Davey, C.L and Wootton, A.B., 2006. Addressing sustain ability early in the urban design process. Management of Environmental Quality: An International Journal, 17(6), pp.689-706. doi: http://dx.doi.org/10.1108/14777830610702520 
Carpenter, J., 2011. Money's too tight to mention? Urban regeneration in a recession and beyond: The case of Oxford. Journal of Urban Regeneration and Renewal, 4(3), pp.228-39.

Carter, K. and Fortune, C., 2007. Sustainable development policy perceptions and practice in the UK social housing sector. Construction Management and Economics, 25, pp.399-408. doi: http://dx.doi.org/10.1080/01446190600922578

Coaffee, J., 2004. Re-scaling regeneration. The International Journal of Public Sector Management, 17(5) pp.443-61. doi: http://dx.doi.org/10.1108/09513550410546615

CLG, 2010. Valuing the Benefits of Regeneration: Economics. Communities and Local Government (CLG). London: Her Majesty's Stationery Office.

CLG, 2009. Transforming Places; Changing Lives - A Framework for Regeneration: Summary of Consultation Responses. Communities and Local Government (CLG). London: Her Majesty's Stationery Office.

CLG, 2008. Transforming Places; Changing Lives: A framework for regeneration. Communities and Local Government (CLG). London: Her Majesty's Stationery Office.

Cruickshank, H. J. and Fenner, R.A., 2007. The evolving role of engineers: towards sustainable development of the built environment. Journal of International Development, 19, pp.111-21. doi: http://dx.doi.org/10.1002/jid.1352

DBIS, 2013. Industrial Strategy: government and industry in partnership. Construction 2025. Department for Business, Innovation and Skills. London: HM Government.

Denzin, N.K. and Lincoln, Y.S., 2008. The Landscape of Qualitative Research. 3rd ed. London, UK: SAGE Publication Ltd.

Dixon, T., 2006. Integrating Sustainability into Brownfield Regeneration: Rhetoric or Reality? - An analysis of the UK Development Industry. Journal of Property Research, 23(3), pp.237-67. doi: http://dx.doi.org/10.1080/09599910600933889

Essa, R. and Fortune, C., 2008. Pre-construction evaluation practices of sustainable housing projects in the UK. Engineering, Construction and Architectural Management, 15(6), pp.514-26. doi: http://dx.doi.org/10.1108/09699980810916960

Evans, J. and Jones, P., 2008. Rethinking sustainable urban regeneration: ambiguity, creativity, and the shared territory. Environment and Planning, 40, pp.1416-434. doi: http://dx.doi.org/10.1068/a39293

Feige, A., Wallbaum, H. and Krank, S., 2011. Harnessing stakeholder motivation: towards a Swiss sustainable building sector. Building Research and Information, 39(5), pp.504-51. DIO: 10.1080/09613218.2011.589788.

Granger, R., 2010. Proceedings of the Institution of Civil Engineers. Urban Design and Planning, 163(DP1), pp.9-16.

Haran, M., Newell, G., Adair, A., McGreal, S. and Berry, J., 2011. The performance of UK regeneration property within a mixed asset portfolio. Journal of Property Research, 28(1), pp.75-95. doi: http://dx.doi.org/10.1080/09599916.2011.548913

HM Treasury, 2011. The Green Book: Appraisal and Evaluation in Central Government. London: Her Majesty's Treasury.

HM Treasury, 2007. Review of sub-national economic development and regeneration. London: Her Majesty's Treasury.

Jack, S. and Breeze, J., 2008. Guide to Evaluating regeneration projects and programmes. Manchester: The Centre for Local Economic Strategies (CLES).

Kazmierczak, A.E., Curwell, S.R and Turner, J.C., 2009. Regeneration of large urban area: assessment methods. Proceedings of the ICE Municipal Engineer, 162(2), pp.117-24. doi: http://dx.doi.org/10.1680/muen.2009.162.2.117

Lawless, P., Overman, H.G. and Tyler, P., 2011. Spatial Economics Research Centre Strategies (SERC) for underperforming places, 2011. (Policy Paper 6). London: SERC.

Littig, B. and Griebler, E., 2005. Social sustainability: a catchword between political pragmatism and social theory. Int. J Sustainable Development, 8(1/2), pp.65-79. doi : http://dx.doi.org/10.1504/IJSD.2005.007375

Lombardi, D.R., Porter, L., Barber, A, and Rogers, C.D.F., 2011. Conceptualising Sustainability in UK Urban Regeneration: a Discursive Formation. Urban Studies, 48(2), pp.273-96. doi: http://dx.doi.org/10.1177/0042098009360690

Mang, P. and Reed, B., 2012. Designing from place: a regenerative framework and methodology. Building Research \& Information, 40(1), pp.23-38. doi: http://dx.doi.org/10.1080/09613218.2012.621341

Mathur, V.N., Price, A.D.F. and Austin, S., 2008. Conceptualizing stakeholder engagement in the context of sustainability and its assessment. Construction Management and Economics, 26(6), pp.601-09. doi: http://dx.doi.org/10.1080/01446190802061233

McQuaid, R.W., Greig, M. and Lindsay, C., 2006. Approaches to Evaluation in Community Regeneration. A Report to Communities Scotland. Edinburgh: Communities Scotland.

OGC, 2007. Achieving Excellence in Construction Procurement Guide. London: Office of Government Commerce.

Petty, N.J., Thomson, O.P. and Stew, G., 2012. Ready for a paradigm shift? Part 1: Introducing the philosophy of qualitative research. Manual Therapy, 17(2012), pp.267-74. doi: http://dx.doi.org/10.1016/j.math.2012.03.006

Pitt, M., Tucker, M., Riley, M. and Longden, J., 2009. Towards sustainable construction: promotion and best practices. Construction Innovation: Information, Process, Management, 9(2), pp.201-24. doi: http://dx.doi.org/10.1108/14714170910950830

Qu, S.Q. and Dumay, J., 2011. The qualitative research interview. Qualitative Research in Accounting \& Management, 8(3), pp. 238-64. doi: http://dx.doi.org/10.1108/11766091111162070 
Raco, M. and Henderson, S., 2009. Flagship Regeneration in a Global City: The Re-making of Paddington Basin. Urban Policy and Research, 27(3), pp.301-14. doi: http://dx.doi.org/10.1080/08111140902968737

Roberts, P., 2000. The Evaluation, Definition and Purpose of Urban Regeneration, In: Roberts, P. and Sykes, H., eds. 2000 Urban Regeneration: A Hand Book. London: SAGE.

Saunders, M., Lewis, P. and Thornhill, A., 2009. Research Methods for Business Students. 5th ed. England: Prentice Hall.

SDC, 2003. Mainstreaming sustainable regeneration: A call to action. A report by the UK Sustainable Development Commission (SDC). London: SDC.

Shen, L., Tam, V.W.Y., Tam, L. and Ji, Y., 2010. Project feasibility study: the key to successful implementation of sustainable and socially responsible construction management practice. Journal of Cleaner Production, 18, pp.254-59. doi: http://dx.doi.org/10.1016/j.jclepro.2009.10.014

Smith, R., 2006. Housing Stock Transfer: Investing in Renewal as a Tool for Sustainable Regeneration. Housing Studies, 21(2), pp.269-82. doi: http://dx.doi.org/10.1080/02673030500484885

Sorrell S. and Holti, K., 2007. Approaching regeneration in partnership: Models for private and public section collaboration. Journal of Urban Regeneration and Renewal, 1(1), pp.37-43.

Turcsanyi, J. and Sisaye, S., 2013. Corporate social responsibility and its link to financial performance. World Journal of Science, Technology and Sustainable Development, 10(1), pp.4-18. doi: http://dx.doi.org/10.1108/20425941311313065

Van Bueren, E. and De Jong, J., 2007. Establishing sustainability: policy successes and failures. Building Research \& Information, 35(5), pp.543-56. doi: http://dx.doi.org/10.1080/09613210701203874

Weber, M., 2008. The business case for corporate social responsibility: A company-level measurement approach for CSR. European Management Journal, 26, pp.247-61. doi: http://dx.doi.org/10.1016/j.emj.2008.01.006

Williams, T., Bouchlaghem, D., Loveday, D. and Law, C., 2013. Principal contractor involvement in post-occupancy evaluation in the UK construction industry. Facilities, 31(1/2), pp.39-55. doi: http://dx.doi.org/10.1108/02632771311292509 